\title{
O DESEMPENHO SOCIOAMBIENTAL NAS EMPRESAS DO SETOR ELÉTRICO BRASILEIRO: UMA QUESTÃO RELEVANTE PARA O DESEMPENHO FINANCEIRO?
}

\author{
Allan Pinheiro Holanda \\ Mestrando em Administração e Controladoria pela Universidade Federal do Ceará - UFC \\ allanpholanda@yahoo.com.br \\ Sylene Ruiz de Almada \\ Mestranda em Administração e Controladoria pela Universidade Federal do Ceará - UFC \\ almadaruiz@hotmail.com \\ Márcia Martins Mendes De Luca \\ Doutora em Controladoria e Contabilidade pela Universidade de São Paulo - USP \\ Professora da Universidade Federal do Ceará - UFC \\ marciadeluca@ufc.br \\ Alessandra Vasconcelos Gallon \\ Doutora em Engenharia de Produção Universidade Federal de Santa Catarina - UFSC \\ Professora da Universidade Federal do Ceará - UFC \\ alegallon@terra.com.br
}

\section{RESUMO}

Nos últimos anos os temas responsabilidade social e ambiental e desempenho financeiro corporativo têm sido focos de várias discussões no âmbito acadêmico. Entretanto algumas pesquisas sobre o relacionamento entre os temas são contraditórias. O estudo tem como objetivo geral investigar a associação entre o desempenho socioambiental e o desempenho financeiro nas empresas do setor elétrico brasileiro listadas na Bolsa de Valores, Mercadorias \& Futuros (BM\&F Bovespa) que publicaram o Balanço Social Ibase referente aos exercícios de 2006 a 2008. Trata-se de pesquisa descritiva, de natureza quantitativa, reunindo uma amostra de 40 empresas. O desempenho social e o ambiental foram mensurados a partir dos indicadores dos balanços sociais. O desempenho financeiro foi mensurado a partir do Retorno Sobre Ativos (ROA). Para a avaliação estatística da associação entre os desempenhos foi utilizada a Análise de Correspondência. Os resultados do teste aplicado na amostra levaram à rejeição das hipóteses da pesquisa, já que um alto desempenho social ou ambiental não necessariamente está associado a um alto desempenho financeiro quando os dois tipos de desempenho se referem ao mesmo exercício. Nenhuma evidência pode ser inferida sobre a associação entre os desempenhos social externo e ambiental e o desempenho financeiro com defasagem de um ano.

Palavras-chave: Desempenho socioambiental; Desempenho financeiro; Teoria dos stakeholders.

\section{THE SOCIAL AND ENVIRONMENTAL PERFORMANCE IN THE COMPANIES OF THE BRAZILIAN ELECTRIC SECTOR: IS IT A MATTER OF RELEVANCE TO THE FINANCIAL PERFORMANCE?}

\begin{abstract}
The social and environmental responsibility and corporate financial performance issues have been the focus of several discussions in the academic in the last years, though some researches on the relationship between these themes are contradictories. The general objective of this study is to investigate the association between socio-environmental performance and financial performance in Brazilian electrical sector companies listed on the BM\&FBovespa and that have published their social report, following the Ibase model, referring to the exercises of 2006 up to 2008. It is a descriptive research, of quantitative nature, that gathers a sample of 40 companies. Environmental and social performances have been measured through social report indicators. Financial performance has been measured through the Return on Asset - ROA. The analysis of correspondence was used for the statistical evaluation of the association between performances. The results of the test applied on the sample provided subsidies to reject the research hypotheses since a high social or environmental performance is not necessarily associated with a high financial performance when the types of performance refer to the same exercise. No evidence can be inferred on the association between external social and environmental performance and financial performance with a validity time.
\end{abstract}

Keywords: Socio-environmental performance; Financial performance; Stakeholders' theory.

Revista de Gestão Social e Ambiental - RGSA, São Paulo, v. 5, n. 3, p. 53-72, set./dez. 2011. 


\section{INTRODUÇÃO}

As transformações socioeconômicas dos últimos vinte anos afetaram de modo significativo o comportamento e a avaliação das organizações. Nas últimas décadas emergiram discussões e providências acerca dos impactos causados pela atividade humana e pelo crescimento econômico no meio ambiente e na sociedade. É possível perceber que algumas organizações vêm abandonando a busca imediatista do lucro e passando a se preocupar também com os impactos de suas atividades operacionais no meio em que atuam. Essa mudança se reveste de uma postura mais ética das organizações, que gradualmente aumentam sua preocupação com a realidade social, cultural e ambiental.

Esse contexto deu margem ao surgimento da Responsabilidade Social Corporativa (RSC), na intenção de garantir à sociedade favoráveis condições de convivência, até mesmo pela incapacidade do Estado de provê-las de maneira equilibrada e adequada. Oliveira (2008) argumenta que "o Estado tem diversos problemas que impedem a efetividade na solução dos problemas sociais e ambientais, como a falta de capacidade institucional e corrupção" (p. 68). Assim, a RSC é utilizada de forma a tentar minimizar as limitações não só do Estado, mas também do mercado para solucionar problemas socioambientais. O Balanço Social, nessa perspectiva, se apresenta como instrumento de gestão e de informação que visa divulgar e prestar contas dos investimentos e das ações praticadas na área socioambiental, tornando pública a responsabilidade social da empresa. $\mathrm{O}$ Balanço Social Ibase reúne os seguintes indicadores: Indicadores Sociais Internos, Indicadores Sociais Externos, Indicadores Ambientais e Indicadores do Corpo Funcional, sendo os três primeiros focos de atenção do presente estudo.

De acordo com López, Garcia e Rodriguez (2007), o sucesso das organizações empresariais está começando a ser definido pela integração de conceitos como qualidade gerencial, administração do meio ambiente, reputação da marca, lealdade dos consumidores, ética corporativa e retenção de talentos. Assim, medidas derivadas desses conceitos são consideradas boas estratégias, que deveriam conduzir a uma melhor gestão e, consequentemente, promover um melhor desempenho financeiro.

Contudo, para alguns estudiosos, como Friedman (1970), o principal objetivo de uma organização consiste em gerar dividendos para os acionistas, razão pela qual as atividades e decisões que não atendam a esse propósito não devem ser implementadas. Segundo esses estudiosos, a teoria dos shareholders deve predominar nas organizações, de maneira que a concretização de ações e decisões que não atendam ao objetivo de maximização da riqueza dos acionistas pode ser considerada violação das obrigações morais dos seus executivos.

Uma posição mais conciliatória entre a criação de valor e a responsabilidade social diz respeito à abordagem da relação entre a maximização do valor e a RSC, citada por Jensen (2001). Segundo o autor, uma organização não consegue maximizar seu valor ignora seus stakeholders, ao mesmo tempo que atender aos stakeholders implica não se afastar do seu objetivo geral, que é maximizar o seu valor.

Nessa perspectiva, foram desenvolvidas inúmeras pesquisas acadêmicas com a finalidade de verificar se de alguma maneira o desempenho socioambiental influencia o desempenho financeiro, muitas das quais apresentaram resultados divergentes.

Do exposto, este estudo procura investigar a associação de duas áreas distintas - a socioambiental e a financeira -, de maneira a responder ao seguinte questionamento: Qual a associação entre o desempenho socioambiental e o desempenho financeiro das empresas?

De acordo com essa problemática e com as considerações de McGuire, Sundgren e Schneeweis (1988), segundo as quais os desempenhos social e ambiental atuais influenciam o desempenho financeiro futuro, o presente estudo levanta as seguintes hipóteses assumidas na tipologia elaborada por McGuire et al. (1988):

Revista de Gestão Social e Ambiental - RGSA, São Paulo, v. 5, n. 3, p. 53-72, set./dez. 2011. 
$H_{1}$ : um alto desempenho social interno atual está associado a um alto desempenho financeiro atual;

$H_{2}$ : um alto desempenho social externo atual está associado a um alto desempenho financeiro atual;

$H_{3}$ : um alto desempenho ambiental atual está associado a um alto desempenho financeiro atual;

$H_{4}$ : um alto desempenho social interno atual está associado a um alto desempenho financeiro futuro;

$H_{5}$ : um alto desempenho social externo atual está associado a um alto desempenho financeiro futuro; e

$H_{6}$ : um alto desempenho ambiental atual está associado a um alto desempenho financeiro futuro.

Portanto, o objetivo geral do presente estudo consiste em investigar a associação entre o desempenho socioambiental e o desempenho financeiro das empresas do setor elétrico brasileiro listadas na Bolsa de Valores, Mercadorias \& Futuros (BM\&FBovespa), que publicaram Balanço Social no modelo do Ibase nos exercícios de 2006 a 2008.

O presente estudo se justifica pela relevância do tema no contexto atual das organizações empresariais e pela busca do melhor entendimento da relação entre os seus desempenhos socioambiental e financeiro, comprovada estatisticamente, ou seja, se é possível vislumbrar associação estatisticamente significativa da performance socioambiental com a performance financeira, representada neste estudo pelas empresas do setor elétrico no Brasil listadas na BM\&FBovespa, o que também confirmaria a eficiência administrativa da teoria dos stakeholders. A escolha das empresas do setor elétrico brasileiro se justifica pela sua atuação no sentido de promover mudanças nas esferas social, ambiental e econômica, já que suas atividades impactam diretamente a realidade em que estão inseridas. Para Almeida e Siqueira (2006), o impacto ambiental do setor elétrico é fundamental para a exigência de publicação do Balanço Social pelas empresas atuantes no segmento. Além disso, em conformidade com Azevedo e Cruz (2008), a análise da responsabilidade social no setor elétrico deve ser mais realçada, por se tratar de um serviço público, passando pela compreensão de que a prestação desse serviço deve atender prioritariamente ao interesse coletivo.

O estudo está estruturado em cinco tópicos, incluindo esta introdução. A seguir, apresenta-se a revisão da literatura, contextualizando-se a RSC, a teoria dos stakeholders, a teoria dos shareholders e estudos empíricos anteriores sobre a relação entre os desempenhos socioambiental e financeiro. No terceiro tópico, vem o procedimento metodológico, seguido dos resultados da pesquisa. No último, apresentam-se as considerações finais.

\section{REFERENCIAL TEÓRICO}

\subsection{Responsabilidade social corporativa (RSC)}

Devido ao processo de globalização e às novas demandas empresariais, intensifica-se a discussão acerca da RSC, já que a ética, a transparência e a responsabilidade são, a cada dia que passa, mais exigidas pelo mercado. Dessa forma, faz-se necessário explorar o assunto com maior profundidade. Com a evolução da RSC, o foco das organizações vem mudando gradualmente, já que, além de se preocupar com a conquista de um melhor desempenho financeiro, as empresas passam a adotar também políticas voltadas para o bem-estar de seus colaboradores e da comunidade. Reis e Medeiros (2009) destacam: 
A evolução das discussões e das pressões acerca da responsabilidade social nas empresas tinha o objetivo de conscientizar os executivos sobre as questões de cunho social e ambiental, e, frente a isso, a expectativa de que as empresas pudessem criar condições para se inserirem de maneira mais harmônica e solidária em questões de interesse da sociedade (p. 8).

O conceito de RSC vem evoluindo ao longo das últimas décadas, tendo como início das discussões a publicação do estudo de Bowen (como citado em Carroll, 1999) sobre a responsabilidade social do empresário. A obra questionava quanto à responsabilidade dos empregados para seguir linhas de ação desejáveis ao desenvolvimento da sociedade e quanto à responsabilidade social das empresas que deveria guiar os negócios do futuro.

Desde a década de 1960, nota-se um significativo crescimento na tentativa de conceituar a RSC, principalmente a partir da definição de Davis (como citado em Carroll, 1999), segundo a qual algumas decisões da empresa socialmente responsável podem ser justificadas por um longo e complicado processo de raciocínio, com boa chance de obtenção de ganhos econômicos no longo prazo. Complementarmente, o autor menciona que a responsabilidade social refere-se à obrigação que têm as pessoas de considerar os efeitos potenciais de suas decisões e ações em todo o sistema social.

No final da década de 1970 surgiu uma das mais respeitadas definições conceituais de RSC, proposta por Carroll (1979) e citada em inúmeros estudos acadêmicos: "A responsabilidade social dos negócios abrange os campos econômico, jurídico, ético e discricionário nas expectativas que a sociedade tem das organizações em um determinado ponto no tempo" (p. 499). O autor sugere um modelo de desempenho social corporativo e enumera itens necessários aos empresários e gestores para garantir uma base conceitual de RSC, entender os motivos para a existência de uma RSC e adquirir capacidade de resposta aos questionamentos.

Carroll (1979) explica que a responsabilidade econômica é fundamental e a base para todas as outras, uma vez que a instituição negócio é a unidade econômica básica da sociedade. $\mathrm{O}$ autor alerta que as responsabilidades legais integram o contrato social entre a empresa e a comunidade, isso porque a sociedade espera que a missão econômica da empresa seja cumprida com observância dos requisitos legais. Já com relação às da terceira categoria, as responsabilidades éticas, o autor acrescenta que, embora não necessariamente estejam codificadas em leis e regulamentações, são esperadas pelos membros da comunidade em relação às empresas, pois a sociedade cria expectativas acima dos requisitos legais em relação aos negócios. A quarta e última categoria refere-se às responsabilidades discricionárias, ou seja, "aquelas em que os negócios têm a liberdade de assumir ou não, uma vez que não há imposição legal ou ética, além de não haver uma mensagem clara da sociedade nesse sentido" (Borba, 2005, p. 33).

Nos anos 1980, Jones (1980) deu início a uma interessante discussão sobre a RSC. Primeiramente, definiu que a "responsabilidade social das empresas é uma noção de que as corporações têm uma obrigação com grupos constitutivos da sociedade que não sejam somente os acionistas, mas além do que o previsto por lei e contrato de união" (p. 59-60). A partir dessa definição, propõe que essa obrigação deve ser adotada voluntariamente e que essa obrigação é ampla, indo além do direito tradicional dos acionistas, para outros grupos sociais, como clientes, empregados, fornecedores e comunidades vizinhas.

Desde a década de 1990, pouco se observa acerca da evolução do conceito de RSC, sendo, nesse momento, construídos novos temas a partir de conceitos relacionados à matéria. Uma importante contribuição para a evolução do tema RSC foi a revisão do modelo de desempenho social corporativo por Wood (1991). O autor explica que para avaliar o desempenho social de uma organização, o pesquisador deve examinar o grau de motivação sob os princípios de responsabilidade social na organização e o grau com que a empresa direciona e executa os seus

Revista de Gestão Social e Ambiental - RGSA, São Paulo, v. 5, n. 3, p. 53-72, set./dez. 2011. 
processos, suas políticas, programas e impactos sociais advindos da responsabilidade social. Seguindo essa linha de raciocínio, diversos acadêmicos tentaram operacionalizar o termo responsabilidade social corporativa, visando possibilitar a elaboração de pesquisas que viessem a identificar alguma relação entre responsabilidade social e desempenho financeiro corporativo. Na opinião de Carroll (1999), seguindo a teoria dos stakeholders, há o surgimento da personalização das responsabilidades sociais, uma vez que se procura identificar os membros da sociedade ou grupos mais importantes para a organização.

Ashley (2002) qualifica a responsabilidade social como uma forma de agregar valor à marca e fortalecer os vínculos comerciais e sociais da empresa, além de gerar valor aos negócios e influenciar positivamente a motivação dos funcionários.

Já no Brasil, um importante passo para estimular o desenvolvimento de práticas de RSC foi a criação, em 1998, do Instituto Ethos de Empresas e Responsabilidade Social, principal referência nacional em RSC. O Instituto Ethos congrega um conjunto de empresas que discute meios de disseminar a cidadania empresarial.

De acordo com o Instituto Ethos (2001), a empresa socialmente responsável vai além da obrigação de respeitar as leis, pagar impostos e observar as adequadas condições de segurança e saúde para os trabalhadores. Percebe-se, então, que as práticas de RSC não se limitam ao âmbito interno da empresa, indo muito além, até alcançar todos os stakeholders e o meio ambiente.

\subsection{Bases teóricas: Teoria dos stakeholders versus Teoria dos shareholders}

Segundo Rezende, Nunes e Portela (2008), pela "ótica dos stakeholders", as empresas e seus gestores têm o compromisso ético de respeitar os direitos de todas as partes direta e indiretamente interessadas pela empresa. Contudo, pela "ótica dos shareholders", as empresas e seus gestores têm a função-objetivo de maximizar o retorno dos sócios ou acionistas da empresa. Freeman (1984) define stakeholders como sendo todas as pessoas que afetem uma empresa ou sejam por ela afetadas. Segundo o Instituto Brasileiro de Governança Corporativa [IBGC] (n.d.), o termo shareholder corresponde a determinado grupo que pode afetar de modo significativo por uma empresa ou ser por ela afetado, composto pelos seus próprios acionistas.

Freeman (1984) assinala que a teoria dos stakeholders pode ser definida como a formulação e a implementação, pelos administradores, de processos que satisfaçam todos os grupos que tenham interesse na empresa. A principal tarefa nesse processo seria gerenciar e integrar os relacionamentos e os interesses dos acionistas e de outros grupos, de modo a assegurar o sucesso da empresa no longo prazo. Em resumo, Freeman (1984) diz que se trata de uma abordagem administrativa que enfatiza o gerenciamento ativo do ambiente do negócio e dos relacionamentos entre os participantes, assim como a consequente promoção dos diferentes interesses.

Segundo Donaldson e Preston (1995), a teoria dos stakeholders se diferencia de outras teorias que abordam o ambiente organizacional, pelo fato de que todas as pessoas ou grupos com interesses legítimos que participam de uma empresa o fazem para obter benefícios. Ou seja, a teoria dos stakeholders não necessariamente parte do pressuposto de que os acionistas constituem o único foco legítimo de controle corporativo e governança. Ainda de acordo com esses autores, a teoria dos stakeholders se revela sob aspectos diversos e alternativos, podendo ser caracterizada como instrumental, descritiva e normativa.

Brenner e Cochran (1991) ensinam que a teoria é utilizada para descrever, e algumas vezes explicar, comportamentos específicos e características das empresas. Em relação ao aspecto instrumental, a teoria é utilizada para identificar conexões, ou a sua ausência, entre a administração dos stakeholders e os objetivos das empresas, como, por exemplo, lucratividade e crescimento. E, por último, a visão normativa, que é utilizada para interpretar a função da empresa, incluindo a

Revista de Gestão Social e Ambiental - RGSA, São Paulo, v. 5, n. 3, p. X-XX, set./dez. 2011. 
identificação de princípios morais e filosóficos que norteiam as operações e a administração das organizações.

Donaldson e Preston (1995) enfatizam que "o aspecto normativo seria o que mais facilmente justificaria a teoria dos stakeholders, já que nele não se assume qualquer hipótese, como no aspecto instrumental, mas sim afirmações categóricas envolvendo questões e valores morais" (p. 79). Evan e Freeman (1988) afirmam que a administração tem o dever de salvaguardar o bem-estar da entidade abstrata que é a empresa. Dessa forma, a empresa teria que balancear as reivindicações dos múltiplos stakeholders, para alcançar esse objetivo. Nas palavras de Donaldson e Preston (1995), a necessidade de atenção simultânea a diversos interesses pressupõe uma função com múltiplos objetivos, que apresentam sérios problemas na definição de critérios lógicos para se tomar decisões e fazer avaliação de desempenho. Segundo esses autores, a gestão baseada nos stakeholders argumenta, principalmente, que deve ser dada atenção simultânea aos stakeholders mais importantes, no estabelecimento da estrutura organizacional, assim como nas políticas gerais e no processo decisório.

Contrária à teoria dos stakeholders, a teoria dos shareholders, ou teoria da maximização da riqueza dos acionistas, segundo Borba (2005) tem suas raízes ligadas às teorias de economia e finanças, corroborando Brealey e Myers (2000), segundo os quais o administrador financeiro deve agir tendo em vista o interesse dos proprietários, elegendo como principal objetivo a maximização do lucro. Esses pensamentos confirmam as afirmações de Friedman (1970), segundo as quais a única responsabilidade da empresa consiste em gerar lucros e riquezas para seus acionistas, tendo, portanto, como responsabilidade o desempenho econômico-financeiro, e que qualquer outra posição irá enfraquecer as empresas e o sistema capitalista.

De acordo com McGuire et al. (1988), a teoria dos shareholders mostra uma relação negativa entre o desempenho financeiro e a responsabilidade social e argumenta que o alto nível de responsabilidade acarreta custos adicionais, deixando as empresas em desvantagem econômica em relação a outras que implementam menos ações e práticas de responsabilidade social. Na opinião de Sundaram e Ikpen (2001), quando se maximiza o valor do acionista, todo o valor da empresa é maximizado, de maneira que só seria possível favorecer os stakeholders se a empresa obtivesse sucesso no longo prazo.

De acordo com Reis e Medeiros (2009), um dos primeiros embates entre a teoria dos stakeholders e a teoria dos shareholders ocorreu nos tribunais americanos, com o caso A. P. Smith Manufacturing Company versus Barlow, em que um grupo de acionistas da empresa buscava ressarcimento de valores doados à Universidade Princeton a título de filantropia. O resultado do julgamento foi favorável à empresa, pois, na opinião dos magistrados, as empresas podem utilizar recursos próprios para estabelecer o desenvolvimento social de seus stakeholders. Passados alguns anos após esse embate, e após a construção de indicadores sociais, que possibilitaram a formação de uma importante massa de dados para a elaboração de estudos, teve início no meio acadêmico o confronto entre as duas teorias (Borba, 2005).

\subsection{Estudos empíricos anteriores}

A indagação acerca da relação entre responsabilidade social corporativa e desempenho econômico-financeiro gerou uma série de pesquisas nacionais e internacionais nos últimos anos, especialmente visando investigar a relação entre os desempenhos socioambiental e financeiro (Moskowitz, 1972; Griffin \& Mahon, 1997; Moore, 2001; Simpson \& Kohers, 2002; Borba, 2005; Bertagnolli, Ott \& Damacena, 2006; Arantes, 2006; Oliveira, Daher \& Oliveira, 2006; Santana, Périco \& Rebelatto, 2006; Kitahara, 2007; Macedo, Sousa \& Sousa, 2007; Alberton \& Costa Júnior, 2007; Azevedo \& Cruz, 2008; Cesar \& Silva Júnior, 2008; Tupy, 2008; Rezende et al., 2008; Machado \& Machado, 2009), muitas das quais apresentaram resultados contraditórios e, algumas vezes, inconsistentes.

Revista de Gestão Social e Ambiental - RGSA, São Paulo, v. 5, n. 3, p. 53-72, set./dez. 2011. 
Um dos primeiros estudos a investigar a relação entre o desempenho socioambiental e o desempenho financeiro foi apresentado por Moskowitz (1972), que selecionou 14 firmas detentoras do que ele acreditava ser uma credencial de boa responsabilidade social, e então calculou a taxa de retorno das ações ordinárias para os primeiros seis meses de 1972, ano da pesquisa. Depois, observou que as 14 empresas tinham apreciado uma média correspondente a 7,28\%, enquanto que o maior índice de mercado, como o Dow-Jones Industrial, tinha apreciado um resultado de 4,4\%; dessa forma, o autor encontrou uma relação positiva entre os desempenhos.

Uma pesquisa internacional de destaque foi a de Simpson e Kohers (2002), que, ao analisar o setor bancário norte-americano, a partir de testes, diferenças de médias e regressões, concluíram que há uma correlação positiva entre o desempenho socioambiental e o desempenho financeiro das empresas.

Contudo, de acordo com Griffin e Mahon (1997), durante 25 anos de pesquisas sobre a relação entre o desempenho socioambiental e o desempenho financeiro não foi alcançado nenhum consenso, pois, de acordo com levantamento feito pelos autores em 51 estudos realizados, foram identificadas relação negativa em 11 deles, nula em 5 e positiva em 24 . Em outros 11 estudos foram encontradas duas ou mais relações entre os desempenhos.

No Brasil, destacaram-se nos últimos anos os estudos de Borba (2005), Kitahara (2007), Farias (2008), Cesar e Silva Júnior (2008) e Machado e Machado (2009).

Borba (2005) analisou a relação entre o desempenho socioambiental e o desempenho financeiro a valores de mercado e a valores contábeis, a partir de um indicador baseado nos dados dos balanços sociais no modelo do Ibase. Na maioria dos períodos analisados, foram identificadas relações predominantemente nulas, utilizando-se indicadores de desempenho socioambiental e de desempenho financeiro de mercado ou contábeis. Entretanto, o autor observou que, quando ocorreram relações significativas entre essas variáveis, a maioria foi positiva, principalmente quando utilizados indicadores financeiros contábeis.

Utilizando uma amostra de 897 balanços sociais no modelo do Ibase no período de 2000 a 2004, publicados por 298 empresas de diversos portes, nacionais e multinacionais, que atuavam no Brasil, Kitahara (2007) identificou relações significativas entre o desempenho financeiro das empresas e seu nível de investimento em ações de responsabilidade social, e também constatou a influência dos investimentos em ações de responsabilidade social nos resultados de lucro ou prejuízo das empresas.

Farias (2008) investigou a relação entre a divulgação ambiental, o desempenho ambiental e o desempenho econômico das empresas brasileiras de capital aberto. Os resultados da pesquisa sugeriram que não há relação significativa entre as variáveis pesquisadas; ou seja, observou-se que a divulgação ambiental é influenciada pelo desempenho ambiental e o desempenho econômico afeta o desempenho ambiental, mas a divulgação ambiental não é afetada pelo desempenho econômico.

Cesar e Silva Júnior (2008) analisaram a relação entre o desempenho socioambiental e o desempenho financeiro. Nesse estudo, os autores mensuraram o desempenho socioambiental a partir dos indicadores extraídos dos balanços sociais. $\mathrm{O}$ desempenho financeiro foi medido por meio do Retorno Sobre Ativos (ROA) e do Retorno Sobre o Patrimônio Líquido (ROE). A partir de regressões, os autores concluíram que o ROA e o ROE possuem relação estatisticamente significante com o desempenho social. Contudo, encontraram uma relação positiva entre o ROA e o desempenho social e uma relação negativa entre o ROE e o desempenho social. Mas, na pesquisa, não foram encontradas evidências de uma relação entre as medidas de desempenho financeiro e as de desempenho ambiental.

Machado e Machado (2009) investigaram se o desempenho financeiro é afetado pelos investimentos em responsabilidade social. Para se descobrir se havia uma diferença significativa nessa questão, foram analisados o desempenho financeiro e os indicadores socioambientais de empresas pertencentes a 15 setores da economia brasileira. Os autores observaram que os 
indicadores sociais apresentaram significância estatística, concluindo que uma melhora nos investimentos sociais proporcionam um melhora no desempenho financeiro. Quanto aos investimentos ambientais, não foram encontrados indícios de que podem acarretar impactos no desempenho financeiro.

Becchetti, Di Giacomo e Pinnacchio (2005) ressaltam que essas diferenças de resultados encontradas em estudos empíricos não necessariamente refletem erros, mas implicam diferenças nas perspectivas (períodos de observação, empresas selecionadas, medidas de desempenho e abordagens metodológicas). Entretanto, como pesquisas têm revelado diferenças significativas, busca-se examinar a associação entre os desempenhos social e ambiental e o desempenho financeiro, testando inclusive a tipologia elaborada por McGuire et al. (1988), segundo os quais os desempenhos social e ambiental atuais influenciam o desempenho financeiro futuro.

\section{MÉTODO DE PESQUISA}

Levando-se em conta o objetivo do estudo, a pesquisa, do tipo descritiva, adota os procedimentos bibliográfico e documental. O estudo tem natureza quantitativa, já que, segundo Martins e Theóphilo (2009), esse tipo de pesquisa utiliza procedimentos estatísticos para organizar, sumarizar, caracterizar e interpretar os dados.

Para responder à questão de pesquisa, a seleção das empresas que compuseram a amostra da pesquisa se deu a partir da população de empresas do setor de energia elétrica listadas na BM\&FBovespa no dia $1^{\circ}$ de junho de 2010 e que no período de 2006 a 2008 publicaram o Balanço Social Modelo Ibase. A utilização do modelo do Ibase - mais utilizado por empresas brasileiras (Alberton, Carvalho \& Crispim, 2004) - teve grande importância, por facilitar a coleta de dados e, principalmente, padronizar os investimentos das empresas em responsabilidade socioambiental.

Assim, 23 empresas foram desconsideradas, por não divulgar o balanço social, de maneira que a amostra compreendeu 40 empresas que divulgaram o demonstrativo no modelo do Ibase em cada um dos três exercícios.

Após a definição do universo amostral do estudo, partiu-se para a coleta das variáveis a serem utilizadas. O desempenho social interno, o desempenho social externo e o desempenho ambiental foram mensurados, respectivamente, a partir dos indicadores sociais internos, dos indicadores sociais externos, excluídos os encargos sociais, e dos indicadores ambientais extraídos dos balanços sociais das empresas.

Já o desempenho financeiro foi mensurado utilizando-se o ROA, calculado a partir do lucro operacional, extraído das demonstrações financeiras padronizadas (Balanço Patrimonial e Demonstração do Resultado do Exercício) disponíveis no portal da BM\&FBovespa, que, de acordo com Assaf Neto (2009), o lucro operacional da empresa representa o lucro antes dos encargos financeiros, significando o lucro efetivo que os ativos das empresas conseguem gerar. Com o intuito de realizar os testes estatísticos para comprovar a validade das hipóteses da pesquisa, foi mensurado o desempenho financeiro para o período de 2006 a 2009.

Para o tratamento dos dados e sua posterior análise, utilizou-se a técnica estatística multivariada Análise de Correspondência (Anacor). De acordo com Fávero, Belfiore, Silva \& Chan (2009), "é uma técnica que exibe as associações entre um conjunto de variáveis categóricas não métricas em um mapa perceptual (perceptual mapping), permitindo, dessa maneira, um exame visual de qualquer padrão ou estrutura nos dados" (p. 272). Essas associações são inferidas com base nas posições das variáveis no mapa perceptual, cuja análise se dá pelo exame das relações de proximidade geométrica das categorias de variáveis (Fávero et al., 2009). Contudo, para garantia de uma correta interpretação dos resultados, deve-se levar em conta que a Anacor apresenta uma natureza essencialmente descritiva, não comportando inferências de causa e efeito. Nesse sentido, Tenenhaus e Young (1985) advertem que, em estudos futuros, outros métodos poderão complementar a Anacor, como, por exemplo, a Análise Discriminante.

Revista de Gestão Social e Ambiental - RGSA, São Paulo, v. 5, n. 3, p. 53-72, set./dez. 2011. 
Devido ao fato de a Anacor utilizar variáveis não-métricas, foi necessário transformar os desempenhos social, ambiental e financeiro em elementos não-métricos por grupamento. Hair, Anderson, Tatham \& Black (2005) assinalam que a Anacor objetiva agrupar variáveis altamente associadas, tendo como consequência a representação das relações entre as categorias das variáveis em um mapa perceptual. Dessa forma, na presente pesquisa as duas primeiras variáveis foram agrupadas em função de suas correlações em baixa, média e alta, uma vez que os desempenhos foram distribuídos em três grupos com quantidades iguais, enquanto a variável do desempenho financeiro foi segmentada em nulo-negativo, baixo, médio e alto, haja vista que o desempenho foi distribuído em quatro grupos com quantidades iguais. Para se verificar a dependência dos dados, deve-se primeiramente utilizar o teste Qui-quadrado $(\chi 2)$, requisito indispensável para a utilização da Anacor.

Para o processamento dos dados, foi utilizado o software estatístico Statistical Package for the Social Sciences (SPSS 15). O presente estudo utilizou nível de significância 10\%, o que corresponde a $90 \%$ de segurança na fidedignidade dos resultados.

Dentre os passos metodológicos desta pesquisa destacam-se: elaboração de uma Tabela de Contingência Simples, isto é, uma tabela simples de dupla entrada, que reproduz a distribuição de frequências; realização de um teste Qui-quadrado para verificar a associação entre variáveis linha e variáveis coluna; análise do valor singular de cada dimensão; determinação da dimensionalidade de projeção; e elaboração do Mapa de Correspondência ou Mapa Perceptual.

Para atender ao objetivo e testar as hipóteses conceituais da presente pesquisa, foram realizados seis testes, sendo três para investigar a associação entre os desempenhos concomitantes (do mesmo ano) e outros três para investigar a associação entre os desempenhos com defasagem temporal de um ano; ou seja, os desempenhos social e ambiental de um ano foram comparados com o desempenho financeiro do ano seguinte (os desempenhos social e ambiental de 2006 foram comparados com o desempenho financeiro de 2007, e assim sucessivamente).

Por fim, destaca-se como uma das principais limitações da pesquisa o fato de que as informações sociais e ambientais - indicadores sociais internos, indicadores sociais externos e indicadores ambientais - extraídas dos balanços sociais divulgados pelas empresas, na sua grande maioria não passaram por um processo de auditoria, já que não há normatização no Brasil exigindo essa providência. Como acontece nas pesquisas empíricas, os resultados do presente estudo estão condicionados à amostra observada, partindo-se do pressuposto da confiabilidade na divulgação das informações pelas empresas. Além disso, a utilização de um intervalo temporal relativamente curto (2006 a 2008) constitui uma limitação.

\section{DESCRIÇÃO E ANÁLISE DOS RESULTADOS}

\subsection{Análise sem defasagem temporal}

Para se investigar a associação entre os desempenhos concomitantes, primeiramente foi elaborada a Tabela de Contingência, da qual se podem inferir as primeiras associações entre os dados, a partir das quantidades de dados identificados na intercessão dos desempenhos. Contudo, a confirmação dessas associações somente pôde ser inferida a partir do mapa perceptual resultante do teste Anacor. financeiro.

A Tabela 1 apresenta a Tabela de Contingência para os desempenhos social interno e

Tabela 1: Tabela de Contingência do Desempenho Social Interno x Desempenho Financeiro

\begin{tabular}{|l|c|c|c|c|}
\hline \multirow{2}{*}{$\begin{array}{l}\text { Desempenho Financeiro } \\
\text { (DF) }\end{array}$} & \multicolumn{4}{|c|}{ Desempenho Social Interno (DSI) } \\
\cline { 2 - 5 } & DSI-Baixo & DSI-Médio & DSI-Alto & Total \\
\hline
\end{tabular}

Revista de Gestão Social e Ambiental - RGSA, São Paulo, v. 5, n. 3, p. X-XX, set./dez. 2011. 


\begin{tabular}{|l|c|c|c|c|}
\hline DF-Nulo-Negativo & 8 & 12 & 10 & 30 \\
\hline DF-Baixo & 8 & 9 & 13 & 30 \\
\hline DF-Médio & 7 & 13 & 10 & 30 \\
\hline DF-Alto & 17 & 6 & 7 & 30 \\
\hline Total & 40 & 40 & 40 & 120 \\
\hline
\end{tabular}

Fonte: Elaborada pelos autores (2010).

De acordo com a Tabela 1, há uma aparente associação entre o desempenho social interno baixo e um desempenho financeiro alto. Pode-se inferir ainda uma certa associação entre um alto desempenho social interno e um baixo desempenho financeiro. Esse resultado corrobora os achados do estudo de Cesar e Silva Júnior (2008), que verificaram haver relação significante inversa entre ROA e os indicadores sociais internos na amostra composta por empresas com ações negociadas na BM\&FBovespa. No estudo mencionado, o resultado da regressão indicou inclusive que "quando os indicadores sociais internos tendem a aumentar, o ROA tende a diminuir, ou vice-versa" (Cesar \& Silva Júnior, 2008, p. 10). financeiro.

Já a Tabela 2 apresenta a Tabela de Contingência para os desempenhos social externo e

Tabela 2: Tabela de Contingência do Desempenho Social Externo x Desempenho Financeiro

\begin{tabular}{|l|c|c|c|c|}
\hline \multirow{2}{*}{$\begin{array}{l}\text { Desempenho Financeiro } \\
\text { (DF) }\end{array}$} & \multicolumn{4}{|c|}{ Desempenho Social Externo (DSE) } \\
\cline { 2 - 5 } DF-Nulo-Negativo & DSE-Baixo & DSE-Médio & DSE-Alto & Total \\
\hline DF-Baixo & 7 & 11 & 12 & 30 \\
\hline DF-Médio & 14 & 11 & 5 & 30 \\
\hline DF-Alto & 7 & 6 & 17 & 30 \\
\hline Total & 12 & 12 & 6 & 30 \\
\hline
\end{tabular}

Fonte: Elaborada pelos autores (2010).

De acordo com a Tabela 2, há uma aparente associação entre as variáveis desempenho social externo alto e desempenho financeiro médio. Percebe-se ainda uma associação entre os baixos desempenhos social externo e financeiro. Esse resultado encontra consonância nos achados do trabalho de Cesar e Silva Júnior (2008), segundo o qual quanto maior o nível de investimento na performance social externa, maior também é o nível de performance financeira das empresas, o que comprova a eficiência da administração baseada na teoria dos stakeholders.

Na Tabela 3 é apresentada a Tabela de Contingência para os desempenhos ambiental e financeiro.

Tabela 3: Tabela de Contingência do Desempenho Ambiental x Desempenho Financeiro

\begin{tabular}{|l|c|c|c|c|}
\hline \multirow{2}{*}{$\begin{array}{l}\text { Desempenho Financeiro } \\
\text { (DF) }\end{array}$} & \multicolumn{4}{|c|}{ Desempenho Ambiental (DA) } \\
\cline { 2 - 5 } & DA-Baixo & DA-Médio & DA-Alto & Total \\
\hline DF-Nulo-Negativo & 11 & 10 & 9 & 30 \\
\hline DF-Baixo & 12 & 9 & 9 & 30 \\
\hline DF-Médio & 3 & 14 & 13 & 30 \\
\hline DF-Alto & 14 & 7 & 9 & 30 \\
\hline Total & 40 & 40 & 40 & 120 \\
\hline
\end{tabular}

Fonte: Elaborada pelos autores (2010).

$\mathrm{Na}$ análise da Tabela 3, pode-se inferir uma associação entre o desempenho ambiental baixo e o desempenho financeiro alto. Na pesquisa de Cesar e Silva Júnior (2008) com empresas com

Revista de Gestão Social e Ambiental - RGSA, São Paulo, v. 5, n. 3, p. 53-72, set./dez. 2011. 
ações negociadas na BM\&FBovespa, os autores verificaram que nem ROA nem ROE têm relação com os indicadores ambientais das empresas.

Com o objetivo de se analisar a dependência entre as variáveis, primeiramente foi realizado o teste Qui-quadrado, conforme ilustrado na Tabela 4.

Tabela 4: Resultados do Teste Qui-quadrado

\begin{tabular}{|l|c|c|c|}
\hline VARIÁVEL & N & VALUE & P-VALUE \\
\hline $\begin{array}{l}\text { Desempenho Social Interno x Desempenho } \\
\text { Financeiro }\end{array}$ & 120 & 11,400 & 0,077 \\
\hline $\begin{array}{l}\text { Desempenho Social Externo x Desempenho } \\
\text { Financeiro }\end{array}$ & 120 & 15,400 & 0,017 \\
\hline $\begin{array}{l}\text { Desempenho Ambiental x Desempenho } \\
\text { Financeiro }\end{array}$ & 120 & 10,800 & 0,095 \\
\hline
\end{tabular}

Fonte: Elaborada pelos autores (2010).

De acordo com as informações da Tabela 4, pode-se inferir que as variáveis desempenho social interno, desempenho social externo e desempenho ambiental guardam relação de dependência com a variável desempenho financeiro, já que seus respectivos $p$-values assumiram valores inferiores ao nível de significância adotado no presente estudo (10\%). Portanto, a partir da relação de dependência encontrada, pode-se efetuar o teste da Anacor, já que esta utiliza o teste Qui-quadrado $(\chi 2)$ para padronizar os valores das frequências e formar a base para as associações.

Por meio da aplicação da normalização simétrica, que possibilita a visualização da relação entre as linhas (desempenho social interno) e as colunas (desempenho financeiro) de forma simultânea, pôde-se elaborar o mapa perceptual, conforme apresentado na Figura 1.

Figura 1: Mapa Perceptual do Desempenho Social Interno x Desempenho Financeiro

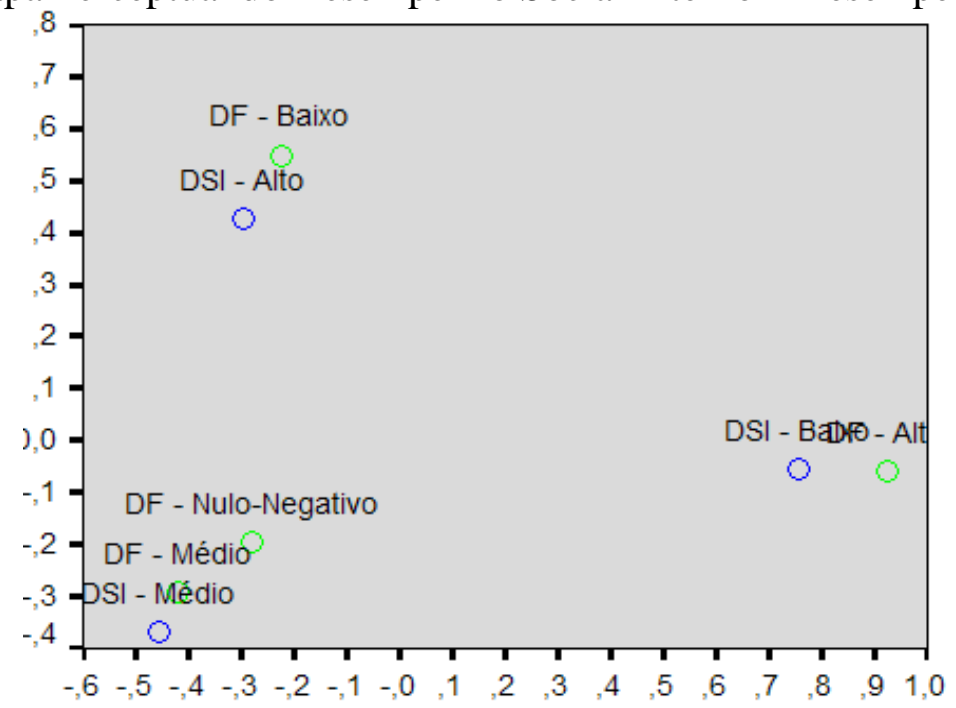

Fonte: Elaborada pelos autores (2010).

De acordo com o mapa perceptual apresentado na Figura 1, é possível identificar algumas associações entre os grupos de desempenho social interno definidos na análise fatorial e os desempenhos financeiros para cada segmento pesquisado.

A partir da proximidade entre as variáveis no mapa perceptual mostrado na Figura 1, constata-se que:

Revista de Gestão Social e Ambiental - RGSA, São Paulo, v. 5, n. 3, p. X-XX, set./dez. 2011. 
- um alto desempenho social interno está associado a um baixo desempenho financeiro;

- um baixo desempenho social interno está associado a um alto desempenho financeiro; e

- um desempenho social interno médio está associado a um desempenho financeiro médio e a um desempenho nulo-negativo, pelo fato de haver certa proximidade entre as variáveis.

Portanto, a partir da análise do mapa perceptual pode-se rejeitar a primeira hipótese conceitual, já que um alto desempenho social interno está associado a um baixo desempenho financeiro.

A seguir, com base na aplicação da normalização simétrica, que possibilita a visualização da relação entre as linhas (desempenho social externo) e as colunas (desempenho financeiro) de forma simultânea, pôde-se elaborar o mapa perceptual, conforme apresentado na Figura 2.

Figura 2: Mapa Perceptual do Desempenho Social Externo x Desempenho Financeiro

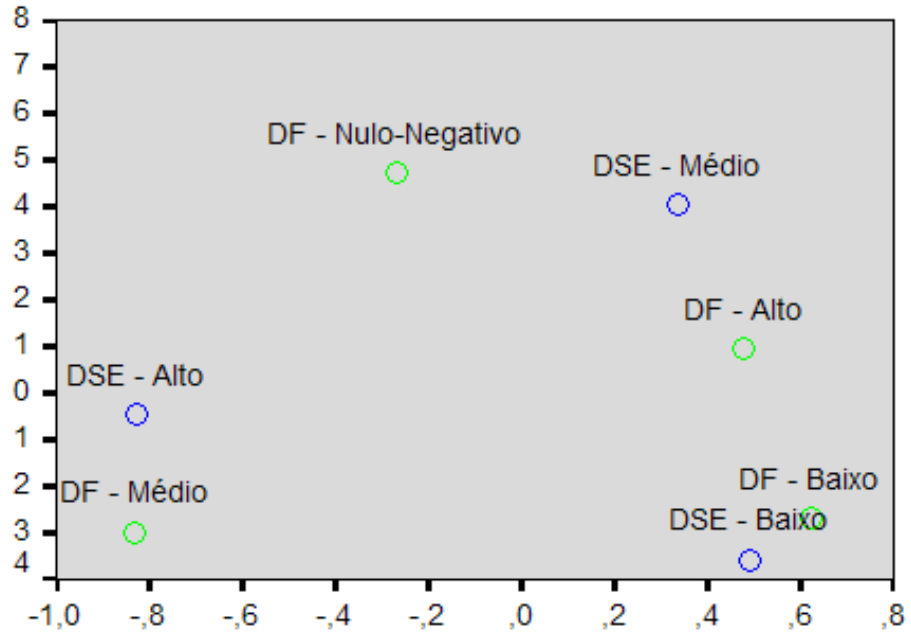

Fonte: Elaborada pelos autores (2010).

De acordo com a Figura 2, constata-se que:

- um alto desempenho social externo está associado a um médio desempenho financeiro;

- um baixo desempenho social externo está associado a um baixo desempenho financeiro; e

- um desempenho social médio externo está associado a um desempenho financeiro alto e a um desempenho nulo-negativo.

Verifica-se, assim, que a segunda hipótese conceitual do presente estudo foi rejeitada, pois, de acordo com os resultados encontrados, um alto desempenho social externo está associado a um médio desempenho financeiro. Em se tratando de pesquisas internacionais, Moore (2001), em estudo do setor de supermercados do Reino Unido, encontrou suporte para a hipótese de sinergia negativa entre os desempenhos social e financeiro. Em outras palavras, confirmou a hipótese de que há uma relação negativa sinérgica ou concomitante entre desempenhos financeiro e social corporativos, conforme os achados da presente pesquisa.

Apesar de as hipóteses 1 e 2 terem sido rejeitadas, cabe ressaltar que alguns estudos constataram que empresas que demonstram desenvolver ações socialmente responsáveis apresentam uma valorização de suas ações superior às daquelas que não adotam tais práticas, como revela a pesquisa de Arantes (2006). Por sua vez, as evidências encontradas no estudo de Rezende et al. (2008) demonstram que apesar de o Índice Bovespa de Sustentabilidade Empresarial (ISE) possuir

Revista de Gestão Social e Ambiental - RGSA, São Paulo, v. 5, n. 3, p. 53-72, set./dez. 2011. 
uma carteira teórica diferenciada, voltada para o tema social, ambiental e ético, o seu retorno é semelhante aos dos índices de ações convencionais.

Em seguida, a aplicação da normalização simétrica possibilitou a visualização da relação entre as linhas (desempenho ambiental) e as colunas (desempenho financeiro) de forma simultânea, podendo-se elaborar o mapa perceptual, conforme revela a Figura 3.

Figura 3: Mapa Perceptual do Desempenho Ambiental x Desempenho Financeiro

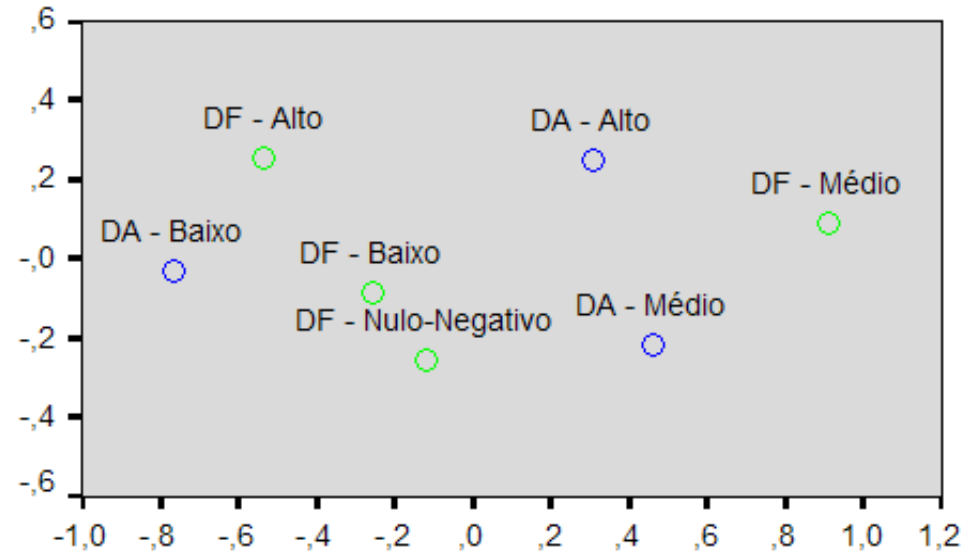

Fonte: Elaborada pelos autores (2010).

De acordo com o mapa perceptual ilustrado na Figura 3, pode-se inferir que:

- $\quad$ um desempenho ambiental alto está associado a um desempenho financeiro médio;

- $\quad$ um desempenho ambiental médio está associado a um desempenho financeiro médio e a um desempenho financeiro nulo-negativo; e

- $\quad$ um desempenho ambiental baixo está associado a um desempenho financeiro alto e a um desempenho financeiro baixo.

Portanto, a terceira hipótese também foi rejeitada, já que, de acordo com os resultados encontrados nos testes empíricos, um desempenho ambiental alto está associado a um desempenho financeiro médio. Na mesma linha de pensamento, no estudo de Tupy (2008) foi possível constatar que as relações entre investimentos socioambientais e as variáveis ROE, valor de mercado e endividamento não foram estatisticamente significantes. Por sua vez, os resultados alcançados no estudo de Santana et al. (2006) identificam forte correlação entre faturamento corporativo e investimento em responsabilidade socioambiental. Interessante destacar que, sob a abordagem da evidenciação ambiental, os resultados empíricos obtidos na pesquisa de Roque e Cortez (2007) em empresas de capital aberto listadas em bolsa, em Portugal, sugerem que as empresas que apresentam um melhor relato ambiental, divulgando informação ambiental qualitativa e quantitativa, são as que apresentam pior performance financeira, o que corrobora resultados alcançados em diversos estudos nacionais anteriores sobre o tema.

\subsection{Análise com defasagem temporal}

No presente tópico, investiga-se a associação entre os desempenhos com o atributo da defasagem temporal de um ano proposto por McGuire et al. (1988). A Tabela 5 apresenta a Tabela de Contingência para os desempenhos social interno e financeiro. 
Tabela 5: Tabela de Contingência do Desempenho Social Interno x Desempenho Financeiro

\begin{tabular}{|l|c|c|c|c|}
\hline \multirow{2}{*}{ Desempenho Financeiro (DF) } & \multicolumn{4}{|c|}{ Desempenho Social Interno (DSI) } \\
\cline { 2 - 5 } & DSI-Baixo & DSI-Médio & DSI-Alto & Total \\
\hline DF-Nulo-Negativo & 7 & 14 & 9 & 30 \\
\hline DF-Baixo & 8 & 10 & 12 & 30 \\
\hline DF-Médio & 9 & 12 & 9 & 30 \\
\hline DF-Alto & 16 & 4 & 10 & 30 \\
\hline Total & 40 & 40 & 40 & 120 \\
\hline
\end{tabular}

Fonte: Elaborada pelos autores (2010).

A partir da Tabela 5, pode-se inferir uma associação entre o desempenho social interno baixo e o desempenho financeiro alto, como constatado na análise sem defasagem temporal (Tabela $1)$.

A Tabela 6 apresenta a Tabela de Contingência para os desempenhos social externo e financeiro.

Tabela 6: Tabela de Contingência do Desempenho Social Externo x Desempenho Financeiro

\begin{tabular}{|l|c|c|c|c|}
\hline \multirow{2}{*}{ Desempenho Financeiro (DF) } & \multicolumn{4}{|c|}{ Desempenho Social Externo (DSE) } \\
\cline { 2 - 5 } & DSE-Baixo & DSE-Médio & DSE-Alto & Total \\
\hline DF-Nulo-Negativo & 11 & 7 & 12 & 30 \\
\hline DF-Baixo & 12 & 9 & 9 & 30 \\
\hline DF-Médio & 7 & 11 & 12 & 30 \\
\hline DF-Alto & 10 & 13 & 7 & 30 \\
\hline Total & 40 & 40 & 40 & 120 \\
\hline
\end{tabular}

Fonte: Elaborada pelos autores (2010).

De acordo com a Tabela 6, verifica-se uma aparente associação entre as variáveis desempenho social externo médio e desempenho financeiro alto. Percebe-se ainda uma associação entre os baixos desempenhos social externo e financeiro, como constatado na análise sem defasagem temporal (Tabela 2).

A Tabela de Contingência para os desempenhos ambiental e financeiro está demonstrada na Tabela 7.

Tabela 7: Tabela de Contingência do Desempenho Ambiental x Desempenho Financeiro

\begin{tabular}{|l|c|c|c|c|}
\hline \multicolumn{1}{|c|}{$\begin{array}{c}\text { Desempenho Financeiro } \\
\text { (DF) }\end{array}$} & \multicolumn{4}{c|}{ Desempenho Ambiental (DA) } \\
\cline { 2 - 5 } DF-Nulo-Negativo & DA-Baixo & DA-Médio & DA-Alto & Total \\
\hline DF-Baixo & 10 & 12 & 8 & 30 \\
\hline DF-Médio & 13 & 6 & 11 & 30 \\
\hline DF-Alto & 6 & 10 & 14 & 30 \\
\hline Total & 11 & 12 & 7 & 30 \\
\hline
\end{tabular}

Fonte: Elaborada pelos autores (2010).

$\mathrm{Na}$ Tabela 7, a Tabela de Contingência para os desempenhos ambiental e financeiro revela uma associação entre o desempenho ambiental alto e o desempenho financeiro médio.

Com o intuito de se investigar a dependência entre as variáveis, foi realizado o teste Quiquadrado, obtendo-se os resultados apresentados na Tabela 8.

Revista de Gestão Social e Ambiental - RGSA, São Paulo, v. 5, n. 3, p. 53-72, set./dez. 2011. 
Tabela 8: Resultados do Teste Qui-quadrado

\begin{tabular}{|l|c|c|c|}
\hline VARIÁVEL & N & VALUE & P-VALUE \\
\hline $\begin{array}{l}\text { Desempenho Social Interno x Desempenho } \\
\text { Financeiro }\end{array}$ & 120 & 4,200 & 0,082 \\
\hline $\begin{array}{l}\text { Desempenho Social Externo x Desempenho } \\
\text { Financeiro }\end{array}$ & 120 & 4,000 & 0,518 \\
\hline $\begin{array}{l}\text { Desempenho Ambiental x Desempenho } \\
\text { Financeiro }\end{array}$ & 120 & 6,000 & 0,238 \\
\hline
\end{tabular}

Fonte: Elaborada pelos autores (2010).

Pelos dados da Tabela 8, pode-se inferir que o desempenho social externo e o desempenho ambiental não guardam relação de dependência com a variável desempenho financeiro; já a variável desempenho social interno possui relação de dependência com a variável desempenho financeiro. Os resultados encontrados no teste Qui-quadrado ( $\chi 2)$ viabilizam a utilização da Anacor somente para a variável desempenho social interno.

Diante do exposto, para desfecho da análise com defasagem temporal, por meio da aplicação da normalização simétrica, que possibilita a visualização da relação entre as linhas (desempenho social interno) e as colunas (desempenho financeiro) de forma simultânea, pôde-se elaborar o mapa perceptual, conforme mostra a Figura 4.

Figura 4: Mapa Perceptual do Desempenho Social Interno x Desempenho Financeiro

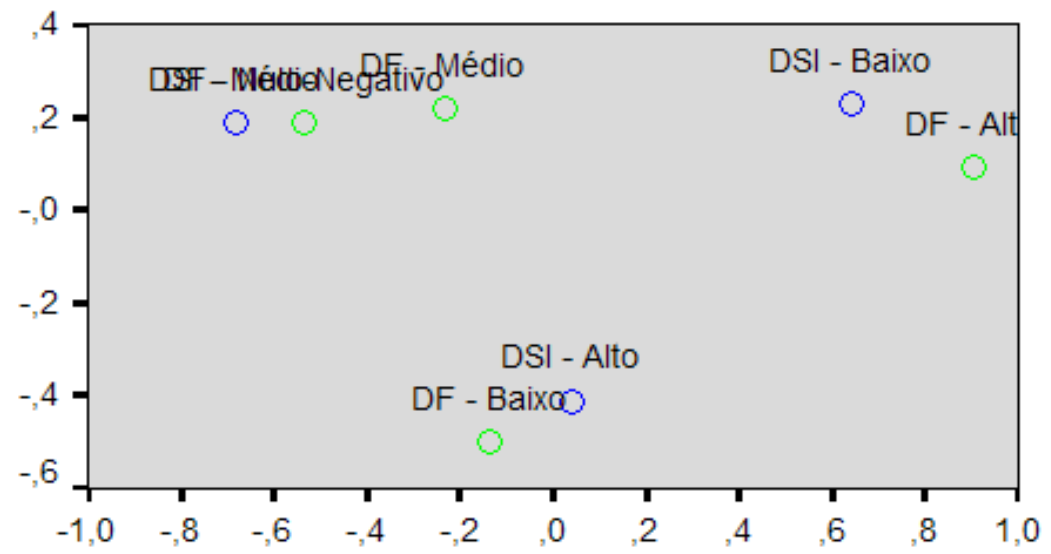

Fonte: Elaborada pelos autores (2010).

A partir da proximidade entre as variáveis no mapa perceptual mostrado na Figura 4, constata-se que:

- um alto desempenho social interno está associado a um baixo desempenho financeiro;

- um baixo desempenho social interno está associado a um alto desempenho financeiro; e

- um desempenho social interno médio está associado a um desempenho financeiro médio e a um desempenho nulo-negativo, pelo fato de haver certa proximidade entre as variáveis.

Dessa forma, a partir da análise do mapa perceptual pode-se rejeitar a quarta hipótese conceitual, pois constatou-se que um alto desempenho social interno está associado a um baixo desempenho financeiro futuro, apesar de o estudo de McGuire et al. (1988) sinalizar a necessidade

Revista de Gestão Social e Ambiental - RGSA, São Paulo, v. 5, n. 3, p. X-XX, set./dez. 2011. 
de se analisar os dois desempenhos (social e financeiro) concomitantemente e com defasagem temporal entre eles. Torna-se importante ressaltar que o referido estudo precursor sugere que o desempenho financeiro, tanto contábil como de mercado, seja um melhor indicador para o nível de responsabilidade social de uma empresa, mas essa análise não foi realizada na presente pesquisa. Não foram encontradas evidências para se inferir sobre a aceitação ou rejeição para a quinta e a sexta hipóteses conceituais.

\section{CONSIDERAÇÕES FINAIS}

A presente pesquisa teve por objetivo verificar a associação entre o desempenho socioambiental e o desempenho financeiro das empresas do setor elétrico brasileiro com ações negociadas na BM\&FBovespa e que publicaram os balanços sociais no modelo do Ibase referentes aos exercícios de 2006 a 2008. O desempenho social interno, o desempenho social externo e o desempenho ambiental foram mensurados, respectivamente, a partir dos indicadores sociais internos; indicadores sociais externos, excluídos os encargos sociais; e indicadores ambientais, extraídos dos balanços sociais das empresas. Por sua vez, o desempenho financeiro foi mensurado a partir do ROA. Para tanto, a análise estatística foi realizada por meio da Análise de Correspondência (Anacor).

Em linhas gerais, os resultados obtidos forneceram subsídios para rejeitar as hipóteses da pesquisa, já que um alto desempenho social ou ambiental não necessariamente está associado a um alto desempenho financeiro concomitante. Além disso, nenhuma evidência pode ser inferida sobre a associação entre os desempenhos social externo e ambiental e o desempenho financeiro com defasagem temporal de um ano.

De forma mais pontual, com base nas análises realizadas na amostra de 40 empresas do setor elétrico listadas na BM\&FBovespa selecionada para este estudo, foi possível inferir as conclusões a seguir.

Sobre as análises efetuadas em relação à associação entre o desempenho socioambiental e o desempenho financeiro verificado no mesmo ano (concomitante) destacam-se os seguintes resultados:

- a primeira hipótese conceitual foi rejeitada, pois, de acordo com os resultados encontrados, um alto desempenho social interno está associado a um desempenho financeiro baixo, associação corroborada por alguns dos estudos empíricos apresentados na revisão da literatura; e

- $\quad$ a segunda e a terceira hipóteses conceituais do presente estudo foram rejeitadas, pois, de acordo com os resultados encontrados, um alto desempenho social externo está associado a um médio desempenho financeiro e um desempenho ambiental alto está associado a um desempenho financeiro médio, o que corrobora parcialmente a eficiência da administração baseada na teoria dos stakeholders.

Apesar de o estudo de McGuire et al. (1988) sinalizar a necessidade de se analisar os dois desempenhos (social e financeiro) com defasagem temporal entre eles, nesta pesquisa os resultados das análises da associação entre o desempenho socioambiental e o desempenho financeiro com o atributo da defasagem temporal de um ano foram capazes de rejeitar a quarta hipótese, pois, um alto desempenho social interno está associado a um baixo desempenho financeiro futuro, semelhante à análise sem defasagem temporal. Não foram encontradas evidências para se inferir sobre a aceitação ou rejeição das demais hipóteses desta pesquisa, já que os resultados do teste Qui-quadrado $(\chi 2)$ revelaram que o desempenho social externo e o desempenho ambiental não guardam relação de dependência com a variável desempenho financeiro futuro.

Revista de Gestão Social e Ambiental - RGSA, São Paulo, v. 5, n. 3, p. 53-72, set./dez. 2011. 
Os resultados não sugerem que as práticas de RSC sejam deixadas de lado pela organização, pois, de acordo com uma posição mais conciliatória entre o desempenho socioambiental e o desempenho financeiro, referida na abordagem da maximização do valor iluminada e na da responsabilidade social corporativa iluminada, citadas por Jensen (2001), uma organização não conseguiria maximizar seu valor se ignorasse seus stakeholders, da mesma forma que, para atender a seus shareholders, a organização não pode se afastar do seu objetivo geral, que consiste em maximizar o seu valor.

Por fim, diante das limitações do estudo, recomenda-se, para pesquisas futuras, aumentar o intervalo temporal e incluir outros setores de atuação, de modo a possibilitar o alcance de resultados mais conclusivos sobre o tema. Além disso, sugere-se, conforme indicado na literatura, o uso de outros métodos, como, por exemplo, a Análise Discriminante, para complementar a Anacor realizada neste estudo.

\section{REFERÊNCIAS}

Alberton, A. \& Costa Jr., N. C. A. (2007). Meio ambiente e desempenho econômico-financeiro: benefícios dos Sistemas de Gestão Ambiental (SGAs) e o impacto da ISO 14001 nas empresas brasileiras. Revista RAC-Eletrônica, 1 (2), p. 153-171.

Alberton, L., Carvalho, F. N. \& Crispim, G. H. (2004). Evidenciação da responsabilidade social/ambiental na perspectiva de um novo contexto empresarial. Anais do Congresso USP de Controladoria e Contabilidade, São Paulo, SP, Brasil, 4.

Almeida, M. M., Siqueira, J. R. M. \& Marques, J. A. V. C. (2006). Uma análise da informação social nas demonstrações contábeis publicadas de empresas do setor de saúde suplementar. Anais do Colóquio Internacional Sobre Poder Local, Salvador, BA, Brasil, 10.

Arantes, E. (2006). Investimento em responsabilidade social e sua relação com o desempenho econômico das empresas. Conhecimento Interativo, 2 (1), p. 03-09.

Ashley, P. A. (Coord.). (2002). Ética e responsabilidade social nos negócios. São Paulo: Saraiva.

Assaf Neto, A. (2009). Finanças corporativas e valor. (4 ${ }^{a}$ Ed). São Paulo: Atlas.

Azevedo, T. C. \& Cruz, C. F. (2008). Evidenciação das informações de natureza socioambiental divulgadas pelas distribuidoras de energia elétrica que atuam na Região Nordeste do Brasil e sua relação com indicadores de desempenho empresarial. Revista Enfoque - Reflexão Contábil, 27 (1), p. 53-66.

Becchetti, L., Di Giacomo, S. \& Pinnacchio, D. (2005). Corporate social responsibility and corporate performance: evidence from a panel of US listed companies. Research Paper Series, 26 (78), p. 1-56.

Bertagnolli, D. D. O., Ott, E. \& Damacena, C. (2006). Estudo sobre a influência dos investimentos sociais e ambientais no desempenho econômico das empresas. . Anais do Congresso USP de Controladoria e Contabilidade, São Paulo, SP, Brasil, 6.

BM\&FBovespa - Bolsa de Valores, Mercadorias \& Futuros (n.d.). Empresas listadas. Recuperado em 01 janeiro, 2001, do http://www.bmfbovespa.com.br/Cias-Listadas/EmpresasListadas/BuscaEmpresaListada.aspx?Idioma=pt-br.

Revista de Gestão Social e Ambiental - RGSA, São Paulo, v. 5, n. 3, p. X-XX, set./dez. 2011. 
Borba, P. R. T. (2005). Relação entre desempenho social corporativo e desempenho financeiro de empresas no Brasil. Dissertação de Mestrado. Faculdade de Economia, Administração e Contabilidade, Universidade de São Paulo, São Paulo, SP, Brasil

Brealey, R. A. \& Myers, S. C. (2000). Principles of corporate finance. (6a Ed). Boston: The Irwin/McGraw-Hill.

Brenner, S. N. \& Cochran, P. (1991). The stakeholder theory of the firm: implications for business and society of firm: implications for business and society theory and research. In: Mahon, J. F. (Ed.). Proceedings of the Intenational Association for Business and Society. Sundace, UT: Internacional Association for Business and Society.

Carrol, A. B. (1979). A three-dimensional conceptual model of corporate performance. Academy of Management Review, 4 (4), p. 497-505.

Carrol, A. B. (1999). Corporate social responsibility. Business and Society, 38 (3), p. 268-295.

Cesar, J. F. \& Silva Júnior, A. (2008). A relação entre a responsabilidade social e ambiental com o desempenho financeiro: um estudo empírico na Bovespa no período de 1999 a 2006. Anais do Congresso Associação Nacional de Pós-Graduação em Ciências Contábeis, Salvador, BA, Brasil, 2.

Donaldson, T. \& Preston, L. E. (1995). The stakeholder theory of the corporation: concepts, evidence and implications. Academy of Management Review, 20 (1), p. 65-91.

Evan, W. \& Freeman, R. E. (1988). A stakeholder theory of the modern corporation: kantian capitalism. Ethical Theory and Business. (5a Ed). Englewood Cliffs: Prentice Hall.

Farias, K. T. R. (2008). A relação entre a divulgação ambiental, desempenho ambiental $e$ desempenho econômico nas empresas brasileiras de capital aberto: uma pesquisa utilizando equações simultâneas. Dissertação de Mestrado. Faculdade de Economia, Administração e Contabilidade Ribeirão Preto, Universidade de São Paulo, Ribeirão Preto, SP, Brasil.

Fávero, L. P., Belfiore, P., Silva, F. L. \& Chan, B. L. (2009). Análise de dados: modelagem multivariada para a tomada de decisões. Rio de Janeiro: Campus.

Freeman, R. E. (1984). Strategic management. Boston: Pitman.

Friedman, M. (1970). The social responsibility of business is increase its profits. New York Magazine, 33, p. 122-126.

Griffin, J. J. \& Mahon, J. F. (1997). The corporate social performance and corporate financial performance debate: twenty-five wears of incomparable research. Business and Society, 36 (1), p. 531.

Hair, J. F., Anderson, R. E., Tatham, R. L. \& Black, W. C. (2005). Análise multivariada de dados. (5a Ed). Porto Alegre: Bookman.

INSTITUTO BRASILEIRO DE GOVERNANÇA CORPORATIVA - IBGC (n.d.). Perguntas frequentes. Recuperado em 01 janeiro, 2001, do http://www.ibgc.org.br/PerguntasFrequentes.aspx.

Revista de Gestão Social e Ambiental - RGSA, São Paulo, v. 5, n. 3, p. 53-72, set./dez. 2011. 
INSTITUTO ETHOS DE EMPRESAS E RESPONSABILIDADE SOCIAL - Instituto Ethos. (2001). Como as empresas podem (e devem) valorizar a diversidade. São Paulo: Instituto Ethos.

Jensen, M. (2001). Value maximization, stakeholder theory, and the corporate objective function. Journal of Applied Corporate Finance, New York, 14 (3), p. 8-21.

Jones, T. M. (1980). Corporate social performance revisited, redefined. California Management Review, 22 (3), p. 59-67.

Kitahara, J. R. (2007). Responsabilidade social e desempenho financeiro das empresas: um estudo empírico utilizando o balanço social padrão Ibase. Dissertação de Mestrado. Faculdade de Economia, Administração e Contabilidade, Universidade de São Paulo, São Paulo, SP, Brasil.

López, M. V., Garcia, A. \& Rodriguez, L. (2007). Sustainable development and corporate performance: a study based on the Dow Jones Sustainability Index. Journal of Business Ethics, 75, p. 285-300.

Macedo, M. A. S., Sousa, A. C. \& Sousa, A. C. C. (2007). Desempenho de empresas socialmente responsáveis: uma análise por índices contábil-financeiros. Revista Produção Online, Edição especial/dez.

Machado, M. A. V. \& Machado, M. R. (2009). Responsabilidade social impacta o desempenho financeiro das empresas? . Anais do Congresso USP de Controladoria e Contabilidade, São Paulo, SP, Brasil, 9.

Martins, G. A. \& Theóphilo, C. R. (2009). Metodologia da investigação científica para Ciências Sociais Aplicadas. São Paulo: Atlas.

McGuire, J. B., Sundgren, A. \& Schneeweis, T. (1988). Corporate social responsibility and financial performance. Academy of Management Journal, 31 (4), p. 854-872.

Moore, G. (2001). Corporate social and financial performance: an investigation in the U.K. supermarket industry. Journal of Business Ethics, 34 (4), p. 299-315.

Moskowitz, M. (1972). Choosing socially responsible stocks. Business and Society, p.71-75.

Oliveira, M. C., Daher, W. M. \& Oliveira, B. C. (2006). Responsabilidade social corporativa e geração de valor reputacional: estudo de multicaso, segundo o modelo de Hopkins, de empresas do setor energético do nordeste brasileiro. Anais do Congresso USP de Controladoria e Contabilidade, São Paulo, SP, Brasil, 6.

Oliveira, J. A. P. (2008). Empresa na sociedade: sustentabilidade e responsabilidade social. Rio de Janeiro: Elsevier.

Reis, C. N. \& Medeiros, L. E. (2009). Responsabilidade social das empresas e balanço social: meios propulsores do desenvolvimento econômico e social. São Paulo: Atlas.

Rezende, I. A. C., Nunes, J. G. \& Portela, S. S. (2008). Um estudo sobre o desempenho financeiro do índice Bovespa de sustentabilidade empresarial. Revista de Educação e Pesquisa em Contabilidade, 2 (1), p. 71-93.

Revista de Gestão Social e Ambiental - RGSA, São Paulo, v. 5, n. 3, p. X-XX, set./dez. 2011. 
Roque, V. \& Cortez, M. C. (2006). A divulgação de informação ambiental e a performance financeira das empresas cotadas em Portugal. Revista de Estudos Politécnicos, 3 (5/6), p. 119-143.

Santana, N. B., Périco, A. E. \& Rebelatto, D. A. N. (2006). Investimento em responsabilidade sócio-ambiental de empresas distribuidoras de energia elétrica: uma análise por envoltória de dados. Revista Gestão Industrial, 2 (4), p. 124-139.

Simpson, G. W. \& Kohers, T. (2002). The link between corporate social and financial performance: evidence from the banking industry. Journal of Business Ethics, 35 (2), p. 97-109.

Sundaram, A. K. \& Ikpen, A. C. (2001, October). The corporate objective revisited. Social Science Research Network, New York.

Tenenhaus, M. \& Young, F. (1985). An analysis and synthesis of multiple correspondence analysis, optimal scaling, dual scaling, homogeneity analysis, and other methods for quantifying categorical multivariate data. Psychometrika, 50 (1), p. 91-119.

Tupy, O. (2008). Investimentos em meio ambiente, responsabilidade social e desempenho econômico-financeiro de empresas no Brasil. Revista de Estudos Politécnicos, 6 (10), p. 73-86.

Wood, D. J. (1991). Corporate social performance revisited. Academy of Management Review. 16 (4), p. 691-718.

Data do recebimento do artigo: 17/2/2011

Data do aceite de publicação: 05/12/2011

Revista de Gestão Social e Ambiental - RGSA, São Paulo, v. 5, n. 3, p. 53-72, set./dez. 2011. 